Original Research Article

\title{
Significance of prescription elements and determination of prescription errors in psychiatry outpatient department of a tertiary care hospital
}

\author{
Pradeep Kumar R.*, Meena K. Nandimath, Aarpith Kamath M.
}

Department of Pharmacology, Rajarajeswari Medical College and Hospital, Bangalore, Karnataka, India

Received: 31 January 2017 Accepted: 28 February 2017

*Correspondence to:

Dr. Pradeep Kumar R.,

Email:

cr.nelamangala@gmail.com

Copyright: () the author(s), publisher and licensee Medip Academy. This is an openaccess article distributed under the terms of the Creative Commons Attribution NonCommercial License, which permits unrestricted noncommercial use, distribution, and reproduction in any medium, provided the original work is properly cited.

\begin{abstract}
Background: Prescription is a paper or electronic document issued by licensed medical practitioner detailing the medicine or medicines to be dispensed for an individually named patient. Psychopharmacology is a rapidly growing field and psychiatrists are exposed to lots of newly introduced drugs. Therefore, this study was carried out to determine the Errors in elements of Prescription in Psychiatry Outpatient Department.

Methods: A cross sectional descriptive, non-interventional study in OPD of Psychiatry Department for 12 weeks, 300 prescriptions was analyzed.

Results: Superscription transcription and subscription was included in almost all the prescriptions. In $244(81.33 \%)$ signature was present. Registration number was written in $177(59.0 \%)$ prescriptions. Only 56 (18.70\%) prescriptions were written in generic name and $49(16.34 \%)$ in capital letter. The dose was written in $241(80.34 \%)$ of the total prescription. The frequency was written for all the drugs in $273(91.0 \%)$ and some drugs in $46(15.34 \%)$ and none of the drugs in $13(4.33 \%)$ of the total prescriptions. Instructions for use was written for all the drugs in $216(72.0 \%)$ and some drugs in $39(13.0 \%)$ and none of the drugs in $45(15.0 \%)$ of the total prescription. Total quantity to be dispensed was written for all the drugs in $284(94.66 \%)$ and some drugs in 9 $(3.0 \%)$ and none of the drugs in 7 (2.33\%) of the total prescription. Polypharmacy was observed only in a quartile of the total prescriptions.

Conclusions: The results of the present study show varied compliance to different elements of prescription writing. Low level of generic prescription observed in this study is a matter of concern. Increased generic prescribing will reduce the cost of medications and promote medication adherence.
\end{abstract}

Keywords: Elements of prescription, Prescription errors, Prospective, Psychiatry

\section{INTRODUCTION}

To improve the overall drug use, especially in developing countries, international agencies like World Health Organization (WHO) and International Network for Rational Use of Drugs (INRUD) have recommended standard drug use indicators' which help us to know the shortcomings in our prescription writing. ${ }^{1,2}$

Medication errors: problems related to strength and frequency of medication, quantity per dose, instructions for use, total quantity to be dispensed, dosage form etc. Prescribing errors are harmful to the patients and in worst cases they may lead to fatality. To avoid errors in prescription and its amelioration, the easiest way of prevention of prescription errors is at the time of writing prescription. $^{3,4}$

All prescriptions must include the name, address, specialty and signature of the prescriber as well as the name, sex, and age of the patient and the strength, quantity, dose, frequency, dosage form and instructions for use of the medication. Adherence by the physician to good quality prescribing will minimize errors and ultimately improve patient's care. Prescribing errors can occur as a result of haste, poor concentration to the patient or on account of illness (in case the patient is unable to deliver the correct information), decision- 
making or the prescription-writing process. Incorrect prescribing habits are common unfortunately.

The burden of illness resulting from psychiatric and behavioural disorders is enormous; although, it remains grossly under represented by conventional public health statistics, which focus on mortality rather than the morbidity or dysfunction. Therefore, this study was carried out to determine the errors of prescription in psychiatry outpatient department of a tertiary care hospital.

\section{METHODS}

As important as is the intellectual process of rational drug selection, the processes of prescription and order writing to convert the choice of drug into medication received by the patient is of almost equal importance.

A prescription $\left(\mathrm{R}_{\mathrm{x}}\right)$ is a health-care program that governs the plan of care for an individual patient and is implemented by a qualified practitioner. ${ }^{5}$ A prescription may be taken as a reflection of the physicians attitude to the disease and the role of the drug in its treatment. It also provides an insight into the nature of the health care delivery system. ${ }^{6}$
The standard means of giving permission for a medication to be provided (or dispensed) to a patient remains the prescription (for outpatients) or the medication order (for inpatients). Prescriptions and medication orders contain the information necessary to provide a patient with a supply of medication. Certain information is required by law and other sets of information are helpful in avoiding errors. Historically, prescriptions were handwritten and given to the patient, who then takes the prescriptions to a pharmacy to be filled. ${ }^{7}$ The prescriber should write out both drug names and instructions, avoiding all abbreviations, and write as legibly as possible. The importance of legible handwriting in the prescription- and order-writing process cannot be overemphasized. At worst, poor handwriting can result in deadly or life-threatening medical errors. At best, it may result in delays in the dispensing of the prescribed medicine. ${ }^{7}$ Prescriptions have legal implications, as they may indicate that the prescriber takes responsibility for the clinical care of the patient and in particular for monitoring efficacy and safety. As medical practice, has become increasingly complex, the scope of meaning of the term prescription has broadened to also include clinical assessments, laboratory tests, and imaging studies relevant to optimizing the safety or efficacy of medical treatment. ${ }^{7}$

Table 1: Important parts of prescription and their necessity in minimizing the prescription errors.

\begin{tabular}{|c|c|c|}
\hline & Need of this Part in Prescription & What Happened if Missed? \\
\hline $\begin{array}{l}\text { Prescriber } \\
\text { information }\end{array}$ & $\begin{array}{l}\text { To authenticate the prescription before dispensing } \\
\text { The prescription is a legal document It can be } \\
\text { used in the court of law }\end{array}$ & $\begin{array}{l}\text { The pharmacist are unable to understand whether } \\
\text { the prescription is genuine or from a quack/ } \\
\text { homeopathic or ayurvedic doctor. }\end{array}$ \\
\hline $\begin{array}{l}\text { Patient } \\
\text { information }\end{array}$ & $\begin{array}{l}\text { For proper identification of a patient and to } \\
\text { determine its age group. It is also essential for } \\
\text { follow-up of patient or to get in touch with the } \\
\text { patient in case of prescribing or dispensing errors }\end{array}$ & $\begin{array}{l}\text { If the name is absent it cannot be Contacted to a } \\
\text { particular patient. So, there is a chance of error } \\
\text { when two patients go to a doctor together and it is } \\
\text { Difficult to trace the patient in case of a dispensing } \\
\text { error }\end{array}$ \\
\hline Date & $\begin{array}{l}\text { To know the validity of prescription and to avoid } \\
\text { unnecessary refilling of the prescription }\end{array}$ & $\begin{array}{l}\text { The Pharmacist cannot identify an old prescription } \\
\text { brought for refill and in many cases not advisable }\end{array}$ \\
\hline Superscription & It is a sign of practice. & $\begin{array}{l}\text { If it is not present then the written piece of paper } \\
\text { does not be consider as a prescription by law. }\end{array}$ \\
\hline Inscription & $\begin{array}{l}\text { Illegible handwriting and too many confusing } \\
\text { similar generic \& brand names cause difficulties } \\
\text { to the Pharmacists to dispensed the drugs. }\end{array}$ & $\begin{array}{l}\text { Chances of errors being increased during } \\
\text { dispensing the drugs by pharmacist. }\end{array}$ \\
\hline Subscription & $\begin{array}{l}\text { For dispensing of correct and proper medication } \\
\text { to the patient }\end{array}$ & Medication errors results \\
\hline Signatura & $\begin{array}{l}\text { Patient needs to know the quantity of tablets/cap/ } \\
\text { liquid \& number of times the medicine needs to } \\
\text { be taken. Oral instructions to patients are most of } \\
\text { the times forgotten The pharmacist can also } \\
\text { counsel the patient }\end{array}$ & $\begin{array}{l}\text { Patient is confused what dose to take and how } \\
\text { often. So, Medication errors results. }\end{array}$ \\
\hline $\begin{array}{l}\text { Prescriber } \\
\text { signature }\end{array}$ & $\begin{array}{l}\text { To confirm authenticity of prescription and to } \\
\text { avoid misuse of blank prescription pads. }\end{array}$ & $\begin{array}{l}\text { If the prescription has been printed, the pharmacist } \\
\text { cannot confirm that it is the doctor who has } \\
\text { actually prescribed the medicine. Misuse of blank } \\
\text { prescription cannot be detected }\end{array}$ \\
\hline
\end{tabular}


$R_{x}$ is a symbol meaning prescription. It is sometimes transliterated as $R_{x}$ or just $R_{x}$. This symbol originated in medieval manuscripts as an abbreviation of the Late Latin verb recipe, the imperative form of recipe, to take or take thus. ${ }^{7}$ Literally, the Latin word recipe means simply Take and medieval prescriptions invariably began with the command to take certain materials and compound them in specified ways. $^{7}$

Folk theories about the origin of the symbol $R_{x}$ note its similarity to the Eye of Horus gods whose protection may have been sought in medical contexts. ${ }^{8}$ The word prescription, from pre- (before) and script (writing, written), refers to the fact that the prescription is an order that must be written down before a compound drug can be prepared. Those within the industry will often call prescriptions simply scripts.

The fact that a prescription instructs someone to take rather than give is not a trivial distinction, but makes clear it is directed at the patient, and is not directly an instruction to anyone else. Prescriptions, when handwritten, are notorious for being often illegible. In the US, medical practitioners sloppy handwriting kills more than 7,000 people annually, according to a July 2006 report from the National Academies of Science's Institute of Medicine (IOM). ${ }^{9}$ Predating modern legal definitions of a prescription, a prescription traditionally is composed of four parts: a superscription, inscription, subscription and signature. ${ }^{10}$ So long as there were medications and a writing system to capture directions for preparation and usage, there were prescriptions. ${ }^{11}$ The concept of prescriptions dates back to the beginning of history. Modern prescriptions are actually extemporaneous prescriptions from the Latin (ex tempore) for at/from time. ${ }^{12}$ Extemporaneous means the prescription is written on the spot for a specific patient with a specific ailment. This is distinguished from a non-extemporaneous prescription that is a generic recipe for a general ailment. ${ }^{12}$

Present work is a prospective, observational study carried out at OPD of Psychiatry Department at a Tertiary care hospital for 12 weeks. Sample size was 300 prescriptions. 300 outpatient prescriptions were collected from Psychiatry OPD of a Tertiary care hospital from $1^{\text {st }}$ April 2016 to $31^{\text {st }}$ June 2016.

The prescriptions were analyzed on the basis of following parameters:

- Demographic data

- Diagnosis

- Number of drugs per patient

- Duration of therapy

- Any specific instructions given to the patients

Information present on the prescription was analyzed for the different elements of prescriptions and rationality.

\section{RESULTS}

Majority $(81 \%)$ of the patients was males and remaining were females in the present study. This shows the demography of the patient population coming to the psychiatry OPD. Although many of the psychiatric conditions have equal incidence in both the genders and some are even more so in females, the patients attending OPDs in most psychiatric centres as well as the indoor patients in psychiatric ward belonged to male gender. This highlights the gender bias prevalent in India and is seen in other South Asian countries as well. ${ }^{13}$

Table 2: Elements of prescription $\mathrm{N}=\mathbf{3 0 0}$.

\begin{tabular}{|lll|}
\hline Element & Present & Absent \\
\hline Superscription & $270(90.00 \%)$ & $30(10.00 \%)$ \\
\hline Inscription & & \\
\hline - $\quad$ Generic Name & $56(18.70 \%)$ & $244(81.30 \%)$ \\
- Capital letter & $49(16.34 \%)$ & $251(83.66 \%)$ \\
- Dose & $241(80.34 \%)$ & $59(19.66 \%)$ \\
\hline Subscription & $286(95.33 \%)$ & $14(4.66 \%)$ \\
\hline Transcription & $290(96.66 \%)$ & $10(3.34 \%)$ \\
\hline
\end{tabular}

Superscription and transcription were included in 270 (90\%) and 290 (96.66\%) of total the prescriptions respectively. Dose was written in 241 (80.34\%) prescriptions and in $286(95.33 \%)$ subscription was written and signature in $244(81.33 \%)$. Only $56(18.70 \%)$ prescriptions were written in generic name and 49 (16.34\%) in capital letter (Table 2).

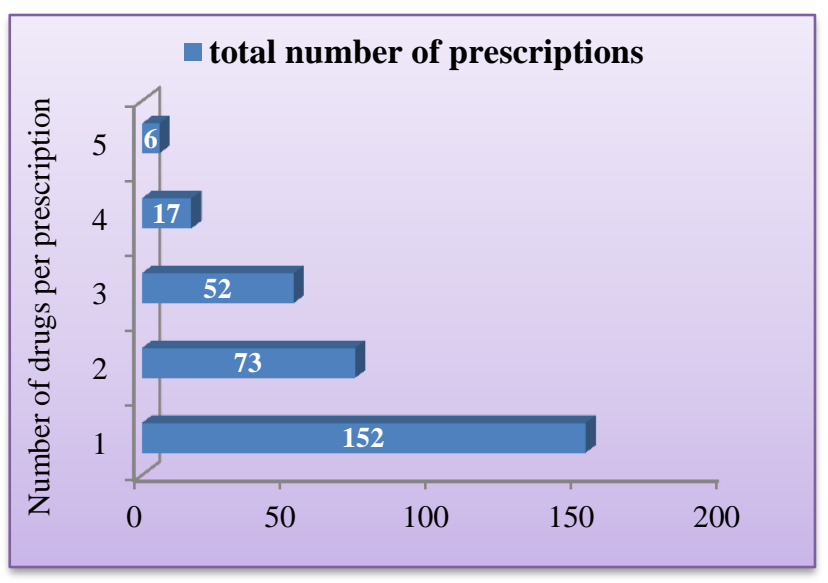

Figure 1: Number of drugs prescribed per prescription.

In the current study, Monotherapy was observed in 152 (50.67\%) followed by prescriptions with two drugs in 73 $(24.34 \%)$ of the total prescriptions. Only 75 patients $(25 \%)$ received 3 or more drugs (Figure 1$)$.

Signature was present in $285(95.0 \%)$ of the prescriptions, Registration number was written in 177 (59.0\%) prescriptions and date was written in nearly all the prescriptions $298(99.34 \%)$ (Table 3$)$. 
Table 3: Prescriber information in the prescriptions observed during the study.

\begin{tabular}{|lll|}
\hline Physician related & No. of prescription & $\%$ \\
N=300 & 285 & 95.00 \\
\hline Signature & 298 & 99.34 \\
\hline Date & 177 & 59.00 \\
\hline Registration number & 177 \\
\hline
\end{tabular}

Table 4: Patient information in the prescriptions observed during the study.

\begin{tabular}{|lll|}
\hline $\begin{array}{l}\text { Patient related } \\
\text { N=300 }\end{array}$ & No. of prescriptions & $\%$ \\
\hline Name & 300 & 100.00 \\
\hline Age & 274 & 91.34 \\
\hline Sex & 297 & 97.34 \\
\hline
\end{tabular}

The name of the patients were mentioned in all the prescriptions, age and sex of the patients were mentioned in $274(91.34 \%)$ and $297(97.34 \%)$ of the total prescriptions respectively (Table 4 ).

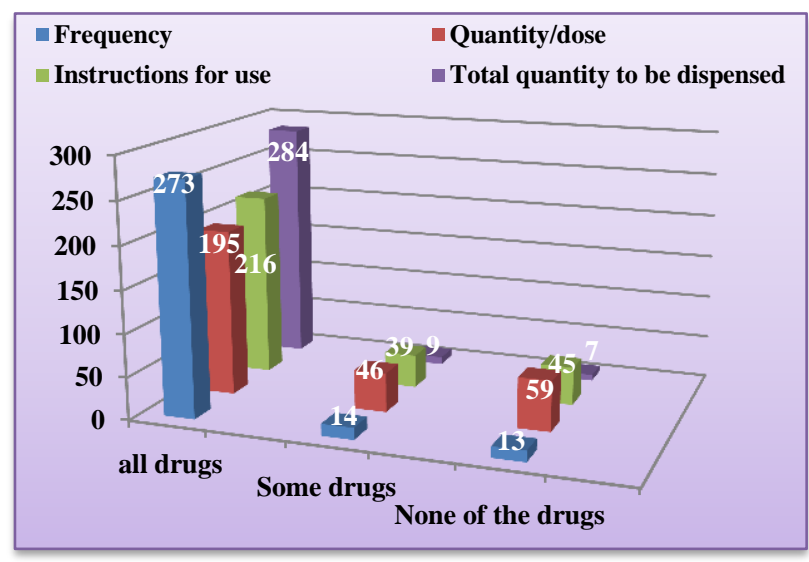

Figure 2: Variables related to drugs in the prescriptions.

The frequency was written for all the drugs in 273 $(91.0 \%)$ and some drugs in $46(15.34 \%)$ and none of the drugs in $13(4.33 \%)$ of the total prescriptions. The dose was written for all the drugs in $195(65.00 \%)$ and some drugs in $46(15.34 \%)$ and none of the drugs in 59 $(19.66 \%)$ of the total prescriptions. Instructions for use was written for all the drugs in $216(72.0 \%)$ and some drugs in 39 (13.0\%) and none of the drugs in 45 (15.0\%) of the total prescription. Total quantity to be dispensed was written for all the drugs in $284(94.66 \%)$ and some drugs in $9(3.0 \%)$ and none of the drugs in $7(2.33 \%)$ of the total prescription (Figure 2).

\section{DISCUSSION}

A written prescription is the prescribers order to prepare or dispense a specific treatment usually medication for a specific patient. When a patient comes for an office visit, the physician or other authorized health professional prescribes medication $67 \%$ of the times and on an average of one prescription per office visit is written because more than one prescription may be written at a single visit. ${ }^{14}$ The average number of drugs per prescription in an audit is an important index of the scope for review and educational intervention in prescribing practices. This is especially important in psychiatry as studies have shown that polypharmacy was common and psychotherapeutic drugs have been over-prescribed and misused. ${ }^{14,15}$

\section{Elements of prescription}

The quantity of medication prescribed should reflect the anticipated duration of therapy, cost and the need continued contact with the physician. The direction of use must be clear and concise to prevent toxicity and to obtain the greatest benefits from therapy. Additional instructions: such as, may cause drowsiness, do not drink alcohol must also be mentioned, if present. All prescription orders should be legible, ambiguous, dated and signed clearly. Furthermore, a good prescription should contain sufficient information to permit the pharmacist to discover errors before the drug is dispensed.

In the present study, the superscription and transcription was included in nearly all the prescriptions. In majority of the prescriptions, subscription was written and signature was present. Ideally all the prescriptions should be signed. Registration number was written in nearly half of the prescriptions. The dose was written in majority of the total prescriptions. The frequency i.e., number of times the drugs is to be taken in a day was written for all the drugs in $91.0 \%$ and some drugs in $4.67 \%$ and none of the drugs in only $4.33 \%$ of the total prescriptions.

Prescribing all drugs by generic names is the recommendation of the WHO. It offers the pharmacist flexibility in selecting the particular drug product to fill the order and offer the patient a potential saving when there is a price difference between identical drugs from different manufacturers. In most states and in most hospitals, the pharmacist has the option of supplying a generically equivalent drug product even if a proprietary name has been specified in the order. It cannot be assumed that every generic drug product is as satisfactory as the trade named product, although examples of unsatisfactory generics are rare. Bioavailability-the effective absorption of the drug product varies between manufacturers and sometimes between different lots of a drug produced by the same manufacturer. In spite of the evidence many practitioners avoid generic prescribing, thereby increasing medical costs. ${ }^{16}$ In this study, only a few of the prescriptions were written in generic name and in capital letter, a matter of great concern.

Brand name drugs are often dispensed when bioequivalent generic alternatives are available, resulting 
in an estimated $\$ 8.8$ billion in excess expenditures per year in the United States. This potentially unnecessary use of brand name drugs may reflect physician and patient beliefs that brand name drugs are superior to their generic counterparts. ${ }^{16}$

However, habitual use of brand name terminology may also play an important role in the dispensing of brandname products, as the name recorded on a prescription can impact whether a drug is dispensed in brand or generic form even when the physician would accept the generic version, and the pharmacy is empowered to provide it. ${ }^{17,18}$ Physicians may prefer brand names for a variety of reasons. Brand names are often more memorable or evocative than generic names and easier to pronounce. Many physicians may be familiar only with the brand name of certain drugs or unaware of the correspondence between generic and brand names. ${ }^{19-21}$

In addition, in certain cases physicians may believe that generic formulations are not as effective as the brand name product. $^{22}$ Although the interchangeability of certain drugs remains a matter of debate many physicians may not be aware of the strict controls imposed by FDA to prove bioequivalence before a generic formulation can be approved. ${ }^{23,24}$ Polypharmacy increases the risk of drug interactions and errors of prescribing.

Fortunately, in the current study, monotherapy was observed in nearly half of the prescriptions. The incidence of polypharmacy was low and only quartile of the patients received 3 or more drugs. This is especially important in psychiatry as studies have shown that polypharmacy was common and psychotherapeutic drugs have been over-prescribed and misused.

\section{CONCLUSION}

Prescription writing is a difficult task. The results of the present study show varied compliance to different elements of prescription writing. This indicates a need for pharmacy and medical educators to demonstrate the importance of writing clear and complete prescriptions. The low level of generic prescription observed in this study is a matter of concern. Increased generic prescribing will reduce the cost of medications and promote medication adherence.

\section{ACKNOWLEDGEMENTS}

The authors thank to the staff of the psychiatry department and pharmacy for their cooperation to conduct this research.

\section{Funding: No funding sources} Conflict of interest: None declared

Ethical approval: The study was approved by the Institutional Ethics Committee

\section{REFERENCES}

1. WHO. How to Investigate Drug Use in Health Facilities: selected Drug Use Indicators, WHO/DAP/93. Volume. 1. Geneva: World Health Organisation; WHO. Drugs and therapeutics committees - a practical guide. Geneva: World Health Organization. 2003;1993:1-87.4. Available from

URL: http://apps.who.int/medicinedocs/en/d/Js4882e/.

2. Joyce GF, Carrera MP, Goldman DP, Sood N. Physician prescribing behavior and its impact on patient-level outcomes. Am J Manag Care. 2011;17:462-71.

3. Lofholm PW, Katzung BG. Rational prescribing and prescription writing. In: Katzung BG, editor. Basic and clinical Pharmacology. 8th ed. New York: McGraw-Hill; 2001:1104-12.

4. Prescription writing. In: British national formulary. London: British Medical Association \& Royal Pharmaceutical Society of Great Britain; 2000.

5. Belknap SM, Moore H, Lanzotti SA, Yarnold PR, Getz M, Deitrick DL et al. Application of software design principles and debugging methods to an analgesia prescription reduces risk of severe injury from medical use of opioids. Clin Pharmacol Ther. 2008;84(3):385-92.

6. Laporte JR. Towards a healthy use of pharmaceuticals. Dev Dialogue. 1985;(2):48-55.

7. Bhattacharya A, Gupta H, Dewangan MK. Prescription Pattern Study Of The Drugs Used In Tertiary Hospitals Of The Bilaspur Region. Asian J Pharm Clin Res. 2012;5(4):73-6. Available from URL: http://www.ajpcr.com/Vol5Supp14/1352.pdf.

8. Selvi PA, Rajkumar S. Branches of Clinical Pharmacology- A Review. Int J Curr Pharm Res. 2012;2(1):14-28. Available from: URL:www.ijcpcr.com/download.php?id=97\&f=97_1 4-28.pd.

9. Khan IN. Systematic review of Prescription writing revisited. Med Pulse-Int Med J. 2014;1(6):262-6.

10. Potter, Samuel OL. Prescription Writing. A Compend of Materia Medica, Therapeutics, and Prescription Writing (sixth ed.). P. Blakiston's Son. 1902.

11. Kumari R, Idris MZ, Bhushan V, Khanna A, Agrawal M, Singh SK. Assessment of Prescription Pattern at the Pubic Health facilities of Lucknow district. Indian J Pharmacol. 2008;40(6):243-7. Available from URL: http://www.ncbi.nlm.nih.gov/pubmed/21279178.

12. Anderson S. Making Medicines: A Brief History of Pharmacy and Pharmaceuticals. London: Pharmaceutical Publishing; 2005 [cited 2016 Aug 2]. Available from: Google books

13. Chakraborty S. Gender bias in South Asia. Econom Politic Weekly. 2001;36(42):3993-5.

14. deGirolamo G, Williams P, Cappiello V. Psychotropic drug utilization and audit in two Italian psychiatric services. Psychol Med. 1987;17:989-97. 
15. Yosselson SS, Sternik D, Liebenzon D. Prescribing patterns in psychiatric hospitals in Israel. Acta Psychiatr Scand. 1979;60(5):477-82.

16. Banahan BF, Kolassa EM. A physician survey on generic drugs and substitution of critical dose medications. Arch Intern Med. 1997;157:2080-8.

17. Mott DA, Cline RR. Exploring generic drug use behavior: the role of prescribers and pharmacists in the opportunity for generic drug use and generic substitution. Med Care. 2002;40:662-74.

18. Suh DC. Trends of generic substitution in community pharmacies. Pharm World Sci. 1999;21:260-5.

19. Hemminki E, Enlund H, Hellevuo K, Laurila R, Turakka H. Trade names and generic names. Problems for prescribing physicians. Scand J Prim Health Care. 1984;2:84-7.

20. Bower AD, Burkett GL. Family physicians and generic drugs: a study of recognition, information sources, prescribing attitudes, and practices. J Fam Pract. 1987;24:612-6.

21. Berberich FR. Cephalosporin trade names. Pediatr Infect Dis J. 2003;22:388-9.

22. Caves R, Hurwitz M. Persuasion or information: promotion and the shares of brand name and generic pharmaceuticals. J Law Econ. 1988;31:299-320.

23. Meredith P. Bioequivalence and other unresolved issues in generic drug substitution. Clin Ther. 2003;25:2875-90.

24. Nightingale SL, Morrison JC. Generic drugs and the prescribing physician. JAMA. 1987;258:1200-4.

Cite this article as: Kumar PR, Nandimath MK, Kamath AM. Significance of prescription elements and determination of prescription errors in psychiatry outpatient department of a tertiary care hospital. Int J Basic Clin Pharmacol 2017;6:978-83. 